\title{
WKD 2016: THE ACCENT ON SPECIFICITY OF KIDNEY DISEASES IN CHILDREN
}

\author{
Marijan SARAGA \\ University Hospital Split, School of Medicine \\ University of Split, Split, Croatia \\ Correspondence: \\ msaraga@kbsplit.hr \\ Tel.: + 38521556303 \\ Fax.: + 38521556509
}

Received: 1 August 2016

Accepted: 5 August 2016

Key words: Children - Chronic kidney disease • Congenital anomalies of kidney and urinary tract.

Renal diseases play an important role in the morbidity of the population. In order to raise awareness of the importance of kidney diseases and their possible negative effects on human health, the World Kidney Day (WKD) is celebrated every year around the world. The celebration of WKD 2016 is dedicated to kidney disease in children, as was emphasized in the article Averting the legacy of kidney disease-focus on childhood (1). Special attention has been drawn to kidney diseases in children because they may begin in the fetal and perinatal period, but also in early childhood and might have serious consequences on health in general or on kidney function in adulthood. The causes of chronic kidney disease $(\mathrm{CKD})$, particularly end stage renal disease (ESRD), in children differ significantly from the causes in adulthood.

It also seems that delivery of premature or small for date newborns may be the cause of late and insidious development of renal disease or arterial hypertension. Congenital anomalies of kidney and urinary tract (CAKUT) are responsible for $40 \%-50 \%$ of ESRD in children, while that number in adulthood is significantly lower (2). As this number has not changed for decades, CAKUT has become a special challenge for scientists. Therefore, concerted efforts are being made to examine the causes of CAKUT and their possible genetic inheritance, aimed at preventing damage caused by CAKUT, such as obstructive uropathy, or urinary tract infections (3).

Ultrasonographic (US) prenatal screening of the urinary tract can detect CAKUT but it has a relatively low sensitivity. While US prenatal screening can detect CAKUT in approximately $1.5 \%$ of all fetuses, postnatal US screening detects another $2.2 \%$ of CAKUT, which were not detected by prenatal US screening (4). This is why postnatal US screening of the urinary system is increasingly used for better detection of CAKUT in some countries of the world. Besides CAKUT, significant causes of CKD and ESRD in childhood involve glomerulonephritis, hereditary nephropathy, hemolytic uremic syndrome (HUS), especially atypical HUS, cystic kidney diseases, and ischemic lesions. Nowadays, it is not enough just to treat kidney diseases but it is also necessary to prevent their occurrence and their progression to CKD and ESRD.

Early detection of proteinuria or arterial hypertension in children is also important 
in the prevention of CKD, especially on the basis of the assumption that proteinuria and arterial hypertension can be treated by ACE-i or ARB (5). The early detection of some rare metabolic diseases such as cystinosis, Fabry disease or cystic kidney diseases, is highly recommended because their treatment has recently become possible or should be possible in the near future, thus enabling the prevention of their late consequences. As knowledge progresses day by day, it has also become possible to influence diseases caused by complement dysfunction, using new drugs that modulate its function or by modern immunosuppressive drugs.

Compared with kidney diseases in adults, kidney diseases in children are very specific due to the fact that children are growing organisms, and are positioned in specific socioeconomic conditions around the world, in which they have variable opportunities to receive help from the health system. Since large differences exist between countries around the world in terms of the availability of drugs, provision of care to sick children, as well as the availability of preventive programs, these factors determine morbidity from kidney diseases or their outcome. While in developing countries diarrhea and severe dehydration are still significant causes of renal ischemia, resulting in subsequently impaired renal function, in developed countries ischemia may only pose problems in premature infants or in children who are born as small for date newborns.

The economic strength of a country may sometimes be crucial for achieving high levels of knowledge of kidney diseases, and expensive and sophisticated diagnostics, as well as for treatment and protection from their adverse consequences. It is already known that the availability of renal replacement therapy (RRT) and kidney transplantation in children is very variable among the countries of the world, depending on the level of orga- nization of the health care system and their economic wealth. Contrary to the popular belief, that the efficacy of treatment of the disease depends on the wealth of the country, it is also known that within the same country wide differences in access to health care may exist, especially in the group of adults (6). A particular problem in the control and treatment of kidney disease in children is the so-called "transitional period" in adolescents with kidney disease. The transition from childhood to adulthood is related to many problems that may have a negative influence on patients with kidney disease, patients on RRT and those with kidney transplants.

Psychological immaturity, non-acceptance of the disease and its treatment, and non-adherence may significantly increase the risk of disease complications, which usually does not happen in other age groups. Since children from younger age groups are generally overprotected by their parents, and well protected by their doctors, adolescents must accept their autonomy and take care of themselves. They have to take over the implementation of their treatment, and obey the advice of doctors, which is sometimes a difficult task to achieve. Obviously, adolescence is marked by extremely poor control of disease due to internal and external psychological causes, and socio-economic and organizational reasons, which result in the significant deterioration in the health control of kidney patients. For this reason "transitional clinics", therapeutic recreation camps or "transitional residential" facilities are organized around the world in order to achieve better awareness of adolescent problems and better adaptation to new conditions of life. This process is neither simple, nor continuous, and it is very individual. Sometimes the transition process must be stopped or delayed, as the end of the process is not the same in all patients involved, and is not always well understood by the caregivers and health system organizations (7). 


\section{Conclusion}

Due to the relatively sparse knowledge on kidney diseases, especially regarding their impact on the individuals and society as a whole, there is a growing need for various registers of kidney disease in different countries. Registers are important for achieving a better overview of which measures have to be taken with regard to better protection of kidney patients. They should improve knowledge and raise awareness of the importance of kidney disease in society, and help in the adoption of measures of protection from kidney diseases, according to the economic possibilities of each country. By raising that kind of awareness, politicians could determine the health priorities in a particular country. However, without the help of scientists, those priorities would not be clearly defined and would therefore remain inaccessible to correction. We are deeply convinced that the politicians of every country in the world, regardless of national income, should recognize children's health problems and place them high on their list of priorities. We, pediatric nephrologists, welcome the inclusion of the problem of children with kidney diseases in the celebration of WKD 2016, because it is a good way to draw attention to the specific, important, treatable and preventable problems connected with kidney diseases in children.
Conflict of interest: The author declares that he has no conflict of interest.

\section{References}

1. Ingelfinger RJ, Kalantar-Zadeh K, Shaefer F. World Kidney Day 2016. Averting the Legacy of Kidney Disease: Focus on Childhood. Paediatrics Today. 2016;12 (1):115-23.

2. Ardissino G, Dacco V, Testa S, Bonaudo R, ClarisAppiani A, Taioli E, et al. ItalKid projectet. Epidemiology of chronic renal failure in children: data from the ItalKid project. Pediatrics. 2003;111(4 Pt 1):e382-7.

3. Sanna-Cherchi S, Kiryluk K, Burgess KE, Bodria M, Sampson MG, Hadley D, et al. Copy-Number Disorders Are a Common Cause of Congenital Kidney Malformations. Am J Hum Genet. 2012;91(6):987-97.

4. Drnasin K, Saraga M. Ultrazvučni probir dojenčadi radi otkrivanja anomalija mokraćnog sustava. Paediatr Croat. 2005;49:7-14.

5. ESCAPE Trial Group; Wuhl E, Trivelli A, Picca S, Litwin M, Peco-Antic A, Zurowska A, et al, Strict blood-pressure control and progression of renal failure in children. $\mathrm{N}$ Engl J Med. 2009;361(17):1639-50.

6. Murray MA, Fialkow J, Andreolli SP, Moe SM. Children with chronic kidney disease: are they insured as adults? Pediatr Nephrol. 2011;26:995-6.

7. Watson AR, Herden P, Ferris M, Kerr PG, Mahan J, Ramzy MF. Transition from pediatric to adult renal services: a consensus statement by the International Society of Nephrology (ISN) and the International Pediatric Nephrology Association (IPNA). Pediatr Nephrol. 2011;26: 1753-7. 